\title{
Responses of thenar muscles to transcranial magnetic stimulation of the motor cortex in patients with incomplete spinal cord injury
}

Nick J Davey, Hazel C Smith, Elizabeth Wells, David W Maskill, Gordana Savic, Peter H Ellaway, Hans L Frankel
Division of

Neuroscience and Psychological Medicine, Imperial College School of Medicine, Charing Cross Hospital, Fulham Palace Road, London, UK

N J Davey

H C Smith

E Wells

D W Maskill

P H Ellaway

National Spinal

Injuries Centre, Stoke

Mandeville Hospital,

Aylesbury,

Buckinghamshire, UK

G Savic

H L Frankel

Correspondence to:

Dr Nick J Davey,

Department of Sensorimotor

Systems,

Division of Neuroscience and Psychological Medicine, Imperial College School of Medicine, Charing Cross Hospital, Fulham Palace Road, London W6 8RF, UK Telephone 0044181846 7284; fax 0044 181 846

7338; email

n.davey@cxwms.ac.uk

Received 8 July 1997 and in revised form 14 October

1997

Accepted

25 November 1997

\begin{abstract}
Objective-To investigate changes in electromyographic (EMG) responses to transcranial magnetic stimulation (TMS) of the motor cortex after incomplete spinal cord injury in humans.

Methods-A group of 10 patients with incomplete spinal cord injury (motor level C3-C8) was compared with a group of 10 healthy control subjects. Surface EMG recordings were made from the thenar muscles. TMS was applied with a $9 \mathrm{~cm}$ circular stimulating coil centred over the vertex. The EMG responses to up to 50 magnetic stimuli were rectified and averaged.

Results-Thresholds for compound motor evoked potentials (cMEPs) and suppression of voluntary contraction (SVC) elicited by TMS were higher $(p<0.05)$ in the patient group. Latency of cMEPs was longer $(p<0.05)$ in the patient group in both relaxed (controls 21.3 (SEM 0.5) ms; patients 27.7 (SEM 1.3) ms) and voluntarily contracted (controls 19.8 (SEM 0.5) ms; patients 27.6 (SEM 1.3) ms) muscles. The latency of SVC was longer $(p<0.05)$ in the patients $(51.8$ (SEM 1.8) $\mathrm{ms})$ than in the controls (33.4 (SEM 1.9) ms). The latency difference (SVC-cMEP) was longer in the patients (25.3 (SEM 2.4) $\mathrm{ms}$ ) than in the controls (13.4 (SEM 1.6) ms). Conclusion-The longer latency difference between cMEPs and SVC in the patients may reflect a weak or absent early component of cortical inhibition. Such a change may contribute to the restoration of useful motor function after incomplete spinal cord injury.
\end{abstract}

(F Neurol Neurosurg Psychiatry 1998;65:80-87)

Keywords: spinal cord injury; magnetic stimulation; electromyography; plasticity

After incomplete spinal cord injury, physiotherapy regimes can have a training effect on muscles in which a degree of function remains. Recovery and compensation may arise as a result of plasticity of CNS function involving neuronal rewiring or regulation of neurotransmission.

The representation of the body within the motor cortex may be modified after amputation in animals ${ }^{12}$ and humans. ${ }^{3-5}$ In humans, some component of the reorganised cortical output is due to unmasking of pre-existing synaptic connections rather than the development of new contacts. ${ }^{6}$ Microstimulation in the rat cortex governing movement of whiskers showed reorganisation of cortical function within hours of motor nerve lesion. ${ }^{7}$

Levy et $a l^{8}$ have reported on two tetraplegic patients who regained some power in proximal muscles of the arm whereas distal muscles remained paretic. With transcranial magnetic stimulation (TMS) of the brain after some recovery they showed that the proximal muscles had a larger than normal scalp field for evoking compound motor evoked potential (cMEP) responses. In a study by Topka et $a l^{9}$ the extent of the motor cortex from which TMS could evoke responses in muscles above a complete spinal transection became enlarged.

The cMEP responses to TMS have longer latencies ${ }^{10}$ and durations ${ }^{11}$ after spinal injury. These changes could be due to slowing of conduction velocity of corticospinal tract axons or selective activation of smaller corticospinal neurons with intrinsically slower axons. Weakness of voluntary muscle contraction in incomplete spinal injury correlates with delayed or absent responses to TMS. ${ }^{12}$ After stroke, a higher incidence of muscle responses with normal threshold and latency was found in response to TMS than to electrical stimulation of the motor cortex. ${ }^{13}$ This result suggests that there is some compensation at a cortical level as it is likely that TMS excites corticospinal neurons indirectly through presynaptic inputs or at the axon hillock, ${ }^{14-16}$ whereas electrical stimulation excites corticospinal axons directly.

TMS in humans has been used to study inhibitory as well as excitatory actions within the CNS. ${ }^{17-21}$ We have shown that voluntary muscle activity may be suppressed by TMS applied over the contralateral motor cortex at a stimulus strength subthreshold for excitation and that a component of this inhibition occurs at the level of the cortex. ${ }^{21}$ It is not known whether inhibitory mechanisms are affected by spinal cord injury. In this study, we have investigated cMEPs and suppression of voluntary contraction (SVC) in response to TMS of the motor cortex in patients with incomplete spinal cord injury and control subjects. A preliminary account of this work has been presented in abstract form. ${ }^{22}$

\section{Methods}

SELECTION OF PATIENTS AND CONTROL SUBJECTS Ethical approval for this study was obtained from the Aylesbury Vale local research ethics 
Clinical details of the patients with incomplete spinal cord injury taking part in the study

\begin{tabular}{|c|c|c|c|c|c|c|c|c|c|c|c|c|c|}
\hline $\begin{array}{l}\text { Patient } \\
\text { No }\end{array}$ & $\begin{array}{l}\text { Age } \\
(y)\end{array}$ & Sex & $\begin{array}{l}\text { Neurological } \\
\text { level (side } \\
\text { tested) }\end{array}$ & $\begin{array}{l}\text { ASIA } \\
\text { grade }\end{array}$ & $\begin{array}{l}\text { Cause } \\
\text { of } \\
\text { injury }\end{array}$ & $\begin{array}{l}\text { Duration of } \\
\text { injury (days) }\end{array}$ & $\begin{array}{l}\text { Antispasticity } \\
\text { medication }\end{array}$ & $\begin{array}{l}\text { Sensory score } \\
\text { light touch } \\
\text { (/112) }\end{array}$ & $\begin{array}{l}\text { Sensory score } \\
\text { pinprick } \\
(/ 112)\end{array}$ & $\begin{array}{l}\text { Motor } \\
\text { score } \\
(/ 100)\end{array}$ & $\begin{array}{l}\text { Motor } \\
\text { grade C8 } \\
\text { (15) }\end{array}$ & $\begin{array}{l}\text { Motor } \\
\text { grade T1 } \\
\text { (/5) }\end{array}$ & $\begin{array}{l}\text { Thenar } \\
\text { MVC } \\
\text { (Newtons) }\end{array}$ \\
\hline 1 & 46 & $M$ & C7 (R) & $\mathrm{D}$ & $\mathrm{T}$ & 176 & $\mathrm{Ba} / \mathrm{da} / \mathrm{di}$ & 62 & 62 & 89 & 4 & 3 & 67 \\
\hline 2 & 72 & $M$ & C3 (L) & C & $\mathrm{T}$ & 156 & $\mathrm{Ba} / \mathrm{da}$ & 74 & 74 & 61 & 1 & 0 & 13 \\
\hline 3 & 57 & $\mathrm{~F}$ & $\mathrm{C} 4(\mathrm{R})$ & $\mathrm{C}$ & $\mathrm{T}$ & 135 & $\mathrm{Da}$ & 88 & 88 & 51 & 2 & 1 & 16 \\
\hline 4 & 71 & $\mathrm{~F}$ & C6 (R) & D & $\mathrm{T}$ & 177 & Nil & 108 & 110 & 92 & 5 & 4 & 52 \\
\hline 5 & 67 & $\mathrm{~F}$ & C3 (R) & C & $\mathrm{T}$ & 182 & $\mathrm{Da}$ & 112 & 89 & 16 & 0 & 0 & 2 \\
\hline 6 & 29 & $M$ & C5 (R) & $\mathrm{D}$ & $\mathrm{T}$ & 188 & $\mathrm{Ba}$ & 64 & 64 & 69 & 3 & 2 & 61 \\
\hline 7 & 40 & $M$ & C6 (R) & $\mathrm{D}$ & $\mathrm{T}$ & 266 & Nil & 86 & 103 & 91 & 4 & 3 & 76 \\
\hline 8 & 28 & $M$ & $\mathrm{C} 4(\mathrm{R})$ & $\mathrm{C}$ & $\mathrm{T}$ & 230 & $\mathrm{Ba} / \mathrm{di}$ & 47 & 47 & 52 & 0 & 0 & 7 \\
\hline 9 & 47 & $\mathrm{~F}$ & $\mathrm{C} 4(\mathrm{R})$ & $\mathrm{A} \dagger$ & NT & 147 & Nil & 22 & 22 & 18 & 1 & 0 & 1 \\
\hline 10 & 72 & $\mathrm{~F}$ & $\mathrm{C} 4(\mathrm{~L})$ & $\mathrm{D}$ & NT & 384 & Nil & 104 & 104 & 79 & 3 & 4 & 21 \\
\hline
\end{tabular}

Neurological assessment was made according to the international standards for neurological and functional classification of the spinal cord. ${ }^{23}$

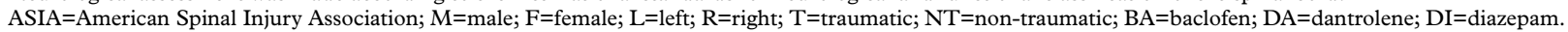
†Complete lesion but with zone of partial preservation at C5-T1.

committee and Charing Cross and Westminster Medical School. All subjects gave their written consent, in accordance with the declaration of Helsinki. Ten control subjects (two men, eight women) aged 27-57 years (mean age 40.1), with no history of neurological disease, took part in the study. Ten patients with incomplete spinal cord lesions (five men, five women) aged $28-72$ years (mean age 52.9) recruited from The National Spinal Injuries Centre, Stoke Mandeville Hospital participated in the study. The table summarises their clinical details. The mean (SEM) heights of the two groups were $166.5(2.1) \mathrm{cm}$ (patients) and 165.6 (1.5) cm (controls). Any antispasticity medication prescribed was noted.

In eight of the patients, the spinal cord lesion had occurred as a result of traumatic injury and in the other two (table, Nos 9 and 10) the lesion had non-traumatic causes. The time lapse between the lesion and recordings ranged from 147 to 384 days (mean 204). The level of the lesion was determined clinically (see later) and is referred to as the most caudal spinal segment with normal motor and sensory function. If the motor and sensory level differed or the level was different on opposite sides of the body, then the motor level on the side of the recording is given. In all the patients this level was rostral to spinal segments $\mathrm{C} 8$ and $\mathrm{T} 1$, the level at which the spinal roots supplying the main components of the ulnar and median nerves innervating the thenar muscles, leave the spinal cord. Neurological examination did not show any peripheral nerve or muscle damage in the patients apart from some wasting of muscle bulk due to disuse. The motor deficits found in the thenar muscles were thus most likely to have been the result of lesions involving upper motor neurons.

\section{MEASUREMENT OF MOTOR AND SENSORY} FUNCTION

Neurological function was assessed by a physician according to international standards for neurological and functional classification of spinal cord injury. ${ }^{23}$ Nine of the patients were motor incomplete (ASIA impairment $\mathrm{scale}^{23}$ grade $\mathrm{C}$ or $\mathrm{D}$ ) below the lesion; one patient (table, No 9) was complete with a zone of partial preservation of motor function between $\mathrm{C} 5$ and T1. An overall motor score out of a possible 100 (100 indicating normal function in all four limbs) was derived (table 1). Force was assessed manually for the finger flexors at the distal phalanx of the middle (third) finger (for level C8) and for the abductor of the little (fifth) finger (for level T1). A grading ranging from $0-5$ was awarded at each level, with a grade of 0 representing no detectable motor function and a grade of 5 normal motor function.

Sensory function was assessed on both sides of the body for light touch (principally testing posterior columns) and pin prick (principally testing spinothalamic pathways) sensitivity over the 28 dermatomes C2 to S4/5. At each level a score of 2 was given for normal sensation, 1 for impaired sensation, and 0 for no sensation. As a result a maximum score of 112 was available for each test.

Before each recording session, the maximum voluntary contraction force in the thenar muscles was measured with a force transducer (Mecmesin advanced force gauge, AFG$500 \mathrm{~N})$. The transducer was hand held by an investigator and each subject was instructed to press as hard as they could against the pressure button by flexing their thumb at the metacarpal phalangeal joint. Three consecutive measurements were made and the largest of the three values was taken to represent the force produced at maximum voluntary contraction. The forces recorded in the patients are listed in the table and correlate well with the neurological assessments of motor function made at spinal levels C8 and T1. Two patients (table, Nos 5 and 8) were given a motor grade of 0 for $\mathrm{C} 8$ (finger flexor of middle finger) and T1 (abductor of little finger); despite this, all patients were able to produce a deflection on the force transducer by contracting their thenar muscles. The mean (SEM) maximum voluntary contractions recorded were: female patients, $18.1(8.9) \mathrm{N}$, male patients $44.5(14.5) \mathrm{N}$, female controls $54.9(6.9) \mathrm{N}$, and male controls $128(19.7) \mathrm{N}$. The large SEM, relative to the mean, in the patient measurements reflects the heterogeneity present in their functional status.

ELECTROMYOGRAPHIC (EMG) RECORDINGS

Electromyograms (EMGs) were recorded from the thenar muscles with self adhesive surface electrodes (Arbo Neonatal Pink). The thenar eminence consists of the following muscle groups: adductor pollicis (innervated by the ulnar nerve), abductor pollicis brevis, and opponens pollicis (innervated by the median nerve) and flexor pollicis brevis (innervated by both the 
median and ulnar nerves). Surface EMG recordings from the thenar eminence would therefore potentially record components of electrical activity from each of these muscles.

When the symptoms were lateralised, the recordings were made from the worst affected side, otherwise the dominant hand was used (all patients were right handed; nine controls were right handed). On this basis, recordings were made from the right thenar muscles in eight patients and nine control subjects and from the left in two patients and one control subject.

The thenar muscles were palpated by the investigator while the subject attempted to make repeated voluntary contractions. This process helped to identify the area of skin covering the largest bulk of muscle and one electrode was placed in this region. The second electrode was placed away from muscle over the proximal phalanx of the thumb. A metal plate covered with conductive jelly was strapped to the forearm to act as an earth electrode. Subjects were seated comfortably in either an armchair or their wheelchair.

The EMG signals were filtered $(-3 \mathrm{~dB}$ below $100 \mathrm{~Hz}$ and above $2 \mathrm{kHz}$ ) and amplified $(\times 1000)$ before being sampled $(4 \mathrm{kHz})$ by a computer for analysis (Cambridge Electronic Design 1401/IBM-compatible PC) and recorded on a digital audio tape (DAT) recorder (Teac, RD 130-T).

The EMG responses to transcranial magnetic stimulation were recorded both with the thenar muscles relaxed and while the subjects maintained a weak voluntary isometric contraction of about $5 \%-10 \%$ of their maximum voluntary contraction. Subjects were provided with audio (loudspeaker) and visual (cathode ray oscilloscope) feedback of their EMG signals to enable them to keep their muscles relaxed or at a constant level of activity during the study.

TRANSCRANIAL MAGNETIC STIMULATION (TMS)

Electromagnetic stimulation of the brain was achieved with a 2 Tesla Magstim 200 stimulator (MagStim Company) connected to a circular $9 \mathrm{~cm}$ (average diameter) stimulating coil centred over the vertex. Cross wires were taped to either side of the stimulating coil to facilitate its accurate placement. The position of the vertex on the scalp of each subject was identified as the point midway between the two tragi and midway between the nasion and inion. The coil was positioned (one or other side up) appropriately so that the induced current in the brain flowed in the required direction ${ }^{24}$ to activate the right or left thenar muscles (clockwise for right hand muscles and anticlockwise for left hand muscles as viewed from above). The stimulus intensity was adjusted to a level that evoked cMEPs on $50 \%$ of stimulus presentations with the thenar muscles relaxed; this intensity was designated as threshold in the relaxed muscle. ${ }^{25}$ The stimulus intensity was increased above threshold, in steps of $5 \%$ of the maximum stimulator output (MSO); up to 50 stimuli were delivered at each strength. This procedure was repeated while the subject made a weak voluntary contraction in the thenar muscles (5\%-10\% maximum voluntary contraction). In this paper threshold for cMEPs is termed $T_{r}$ in relaxed muscles and $T_{c}$ during weak voluntary contraction. Threshold for SVC is termed $\mathrm{T}_{\mathrm{svc}}$.

SIGNAL AVERAGING AND MEASUREMENT OF MOTOR RESPONSES TO TMS

Unrectified and full wave rectified EMG signals were averaged, with reference to the time of the stimulus, with Cambridge Electronic Design signal averaging software (SIGAVG). The latency of the cMEP response was measured from the averaged rectified records with the muscles relaxed and during periods of weak voluntary contraction.

Specifically, we assessed the latency and area of the cMEP, during weak voluntary contraction, from records produced with a stimulation strength just above threshold, termed $\mathrm{TMS}_{\text {low }}$ and at a strength substantially above threshold, termed TMS ${ }_{\text {high. }}$. The TMS $\mathrm{T}_{\text {low }}$ and TMS $\mathrm{T}_{\text {high }}$ were determined, on line, relative to a rough estimate of the cMEP threshold and were expressed later relative to $T_{c}$. Thus, inevitably, the relative values were slightly different in different subjects. The mean (SEM) intensity used at $\mathrm{TMS}_{\text {low }}$ was $1.16 \mathrm{~T}_{\mathrm{c}}(0.02)$ in control subjects and $1.13 \mathrm{~T}_{\mathrm{c}}(0.02)$ in patients and at TMS $_{\text {high }}$ it was $1.5 \mathrm{~T}_{\mathrm{c}}(0.04)$ in control subjects and $1.45 \mathrm{~T}_{\mathrm{c}}(0.04)$ in patients.

The latency of SVC ${ }^{21}$ was measured from the stimulus to the point in the record where the EMG fell consistently below mean background levels. The presence or absence of SVC was assessed by eye and if there was no identifiable decrease in background EMG after averaging the responses from 50 stimuli, the stimulus intensity was deemed to be below threshold for SVC. Weak, infrequent excitatory responses within the variable ongoing EMG of a voluntary contraction may not be rectified about a true zero reference level and may be missed or even be misinterpreted as inhibition. ${ }^{26}$ We therefore also examined averages of unrectified EMG traces to ensure that a period of inhibition was not preceded by a small facilitatory response.

\section{STATISTICAL ANALYSES}

Statistical analyses were performed with Mann-Whitney rank sum tests, or for paired data, Wilcoxon signed rank tests.

\section{Results}

FORM OF RESPONSES

Figure 1 shows typical responses to TMS produced during weak voluntary contraction in a control subject (records $\mathrm{A}$ and $\mathrm{B}$ ) and in a patient (records C and D).

The cMEP responses are identifiable on the records as an upward deflection (starting at a point marked by the dashed vertical lines) from the mean level of voluntary EMG activity (indicated by the dashed horizontal lines) in the control subject (fig 1A) and the patient (fig 1C) for a stimulus intensity just above threshold $\left(T_{c}\right)$. In figure $1 \mathrm{~B}$ and $\mathrm{D}, \mathrm{SVC}$ is evi- 

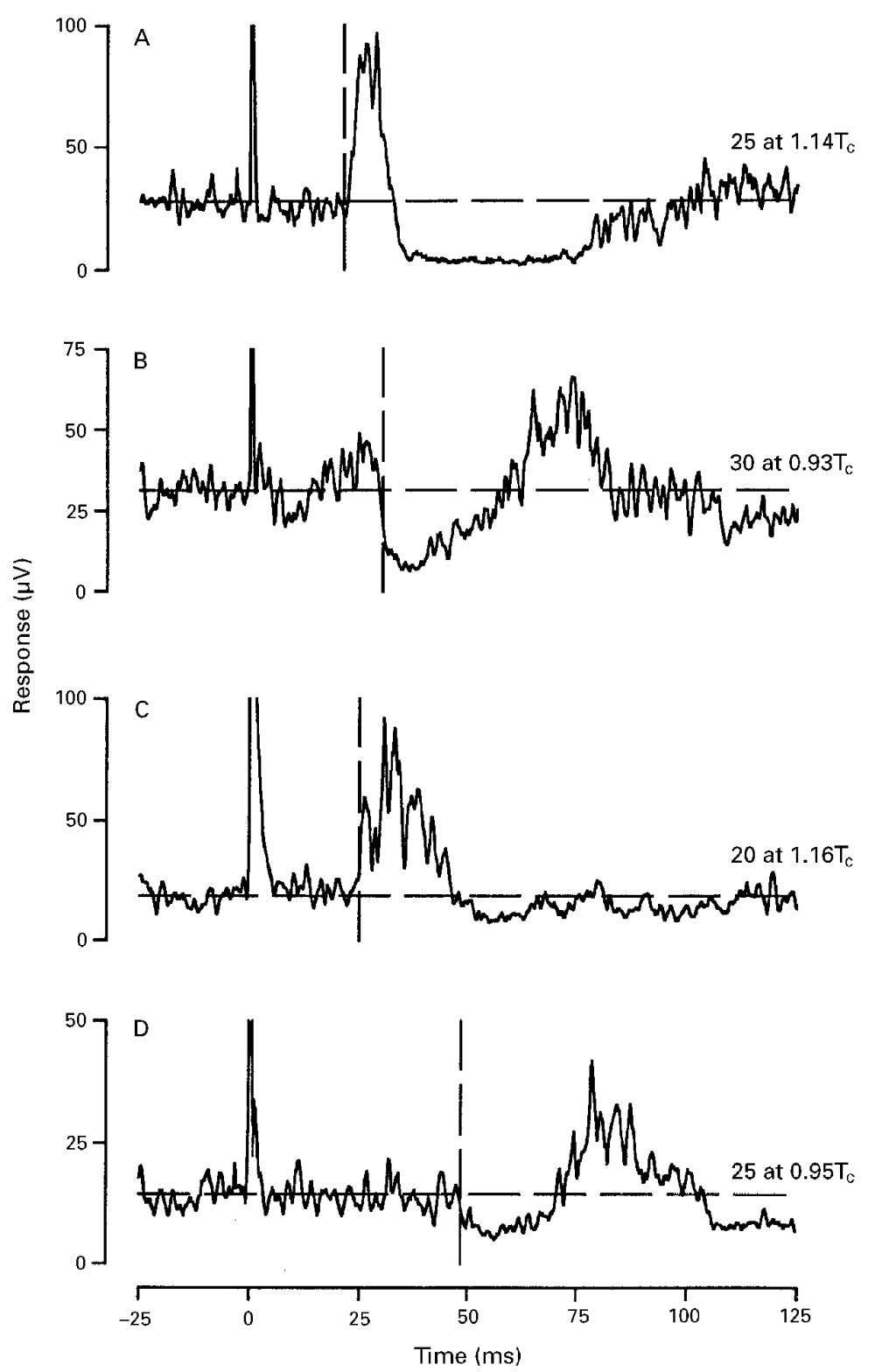

Figure 1 Averaged rectified EMG responses of the thenar muscles to TMS delivered during weak isometric voluntary contraction. Records $A$ and $B$ are from a control subject and records $C$ and $D$ from a patient (table 1, No 1). The number of responses averaged and the stimulus intensity with respect to $T_{c}$ is indicated on each record. The horizontal dashed lines indicate the mean level of voluntary EMG activity assessed from the $25 \mathrm{~ms}$ period preceding the stimulus. The vertical dashed lines mark the onset latency for $c M E P s$ (records $A$ and $C$ ) or $S V C$ (records $B$ and $D)$. Note differences in $y$ axis scaling.

dent (onset marked by vertical dashed lines) in the control subject (B) and the patient (D) in response to TMS at a strength below $\mathrm{T}_{\mathrm{c}}$.

THRESHOLD FOR RESPONSES

In figure 2 thresholds are expressed in terms of percentage of the maximum stimulator output (\%MSO). The mean (SEM) threshold for evoking cMEP responses fell significantly $(\mathrm{p}<0.01)$ when people made a weak voluntary contraction. In the control subjects the mean values were $40.4(2.8) \% \mathrm{MSO}$ for $\mathrm{T}_{\mathrm{r}}$ and 31.8 (1.6) \%MSO for $T_{c}$ whereas in the patients they were 59.5 (5.5) \% MSO for $\mathrm{T}_{\mathrm{r}}$ and 40.9 (3.5) \%MSO $T_{c}$. The mean thresholds for evoking cMEPs were significantly higher in the patients than control subjects both in relaxation $(\mathrm{p}<0.05)$ and during weak voluntary con-

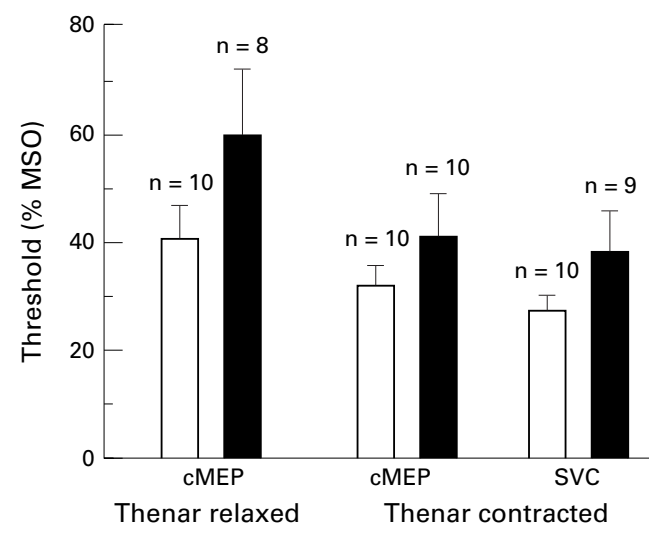

Figure 2 Mean threshold stimulus intensities to TMS for cMEPs in thenar muscles while relaxed $\left(T_{r}\right)$ and for producing cMEPs or SVC during weak isometic voluntary contractions $\left(T_{c}\right)$. Stimulus intensity is expressed as percentage of maximum stimulator output (\%MSO). Open bars represent data from control subjects and closed bars data from patients; the number of subjects is given above each bar. Error bars indicate SEM.

traction $(p<0.05)$ of the thenar muscles. The cMEP responses could not be evoked in the relaxed muscle of two patients (table, Nos 6 and 10 ) with a stimulus intensity of $70 \% \mathrm{MSO}$; the patients requested that we did not increase the intensity above this strength.

Mean values for $T_{\text {svc }}$ were lower than $T_{c}$ in both controls $\left(\mathrm{T}_{\mathrm{c}} 31.8(1.6) \% \mathrm{MSO}, \mathrm{T}_{\mathrm{svc}} 26.9\right.$ (1.3) \%MSO) and patients ( $\mathrm{T}_{\mathrm{c}} 40.9$ (3.5) $\% \mathrm{MSO}, \mathrm{T}_{\mathrm{svC}} 38.0$ (3.3) \%MSO) but these differences were not significant $(\mathrm{p}>0.05)$. In two of the patients (table, Nos 5 and 8 ) SVC could not be evoked at stimulus strengths below $T_{c}$ and was only found after a cMEP. In a further patient (table, No 3) and three control subjects there was no discernable difference between $T_{c}$ and $\mathrm{T}_{\mathrm{svC}}$. In one patient (table, No 9) SVC was not seen at all; however, this patient had a very low maximum voluntary contraction which made suppression of the EMG signal difficult to detect. The mean value of $T_{\mathrm{svc}}$ was significantly $(p<0.05)$ higher in the patients (38 (3.3) \%MSO) than in the control subjects (26.9 (1.3) \%MSO).

\section{LATENCY OF RESPONSES}

The latencies of cMEPs were assessed at mean (SEM) stimulus intensities as follows: control subjects with muscle relaxed $1.36 \mathrm{~T}_{\mathrm{r}}(0.03)$, control subjects with muscle contracted $1.5 \mathrm{~T}_{\mathrm{c}}$ (0.04), patients with muscle relaxed $1.19 \mathrm{~T}_{\mathrm{r}}$ (0.04), and patients with muscle contracted $1.44 \mathrm{~T}_{\mathrm{c}}(0.04)$.

Figure 3 shows that the mean (SEM) latency of the cMEP response in control subjects was significantly $(\mathrm{p}<0.01)$ shorter when the muscle was contracted $(19.8(0.5) \mathrm{ms})$ than when it was relaxed $(21.3(0.5) \mathrm{ms})$. This latency difference was not present in the patient group (relaxed 27.7 (1.3) ms; contracted 27.6 (1.3) ms; $p>0.05)$. However, the mean latency of cMEPs was significantly $(p<0.01)$ longer in the patient group than in the control subjects in both relaxed and contracted conditions. Inspection of individual responses showed no appreciable jitter in the latency of cMEPs in either the patient or control group. 


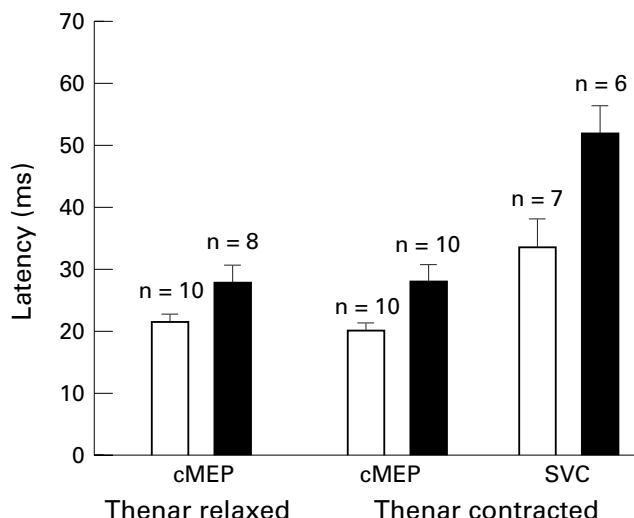

Figure 3 Mean onset latency for $c M E P$ responses in relaxed and activated thenar muscles and for SVC in the absence of preceding $c M E P$ s. Open bars represent data from control subjects and closed bars from patients; the number of subjects is given above each bar. Error bars indicate one $S E M$. Note the larger latency difference between $c M E P$ s and SVC in the patients.

The latency of SVC was assessed at the lowest stimulus intensity at which the response was clearly identifiable (fig 3). This stimulus strength was below $\mathrm{T}_{\mathrm{c}}$ in seven of the 10 control subjects $\left(0.85 \mathrm{~T}_{\mathrm{c}}(0.03)\right.$ and six of the 10 patients $\left(0.93 \mathrm{~T}_{\mathrm{c}}(0.02)\right.$.

In these seven control subjects and six patients the mean (SEM) latency of SVC was significantly $(\mathrm{p}<0.01)$ longer in the patients (51.8 (1.8) $\mathrm{ms}$ ) than in the control subjects (33.4 (1.9) $\mathrm{ms})$.

When the latency of the cMEP response was subtracted from the latency of SVC, the latency difference was, on average, significantly $(p<0.01)$ longer (almost twice as long) in the patients (25.3 (2.4) ms; $\mathrm{n}=6)$ than in the control subjects $(13.4(1.6) \mathrm{ms} ; \mathrm{n}=7)$. The longer latency difference can be appreciated in figure 1 if the control subject (A and B) is compared with the patient (C and $D)$.

DURATION OF RESPONSES

The mean (SEM) duration of cMEPs in the patients (relaxed 17.2 (1.9) ms; contracted 24.8 (3.2) ms) was not significantly different $(\mathrm{p}>0.05)$ from the control subjects (relaxed 19.5 (1.6) ms; contracted 17.4 (2.3) ms). There was no significant difference $(\mathrm{p}>0.05)$ in mean duration of cMEPs in either group between the relaxed and contracted states. The duration of averaged cMEPs in the patient group had a wider range than in control subjects. A contributing factor to the longer duration of the averaged cMEP found in some patients could have been jitter in the latency of individual responses. As mentioned earlier, inspection of such individual cMEPs showed jitter was not present.

The duration of the SVC varied widely between people. When duration was compared in those where SVC could be identified in the absence of preceding cMEPs the mean (SEM) duration in the patients (15.7 (3.3) $\mathrm{ms} ; \mathrm{n}=6$ ) was no different $(P>0.05)$ from that in the control subjects (17.3 (3.5) $\mathrm{ms} ; \mathrm{n}=7$ ).
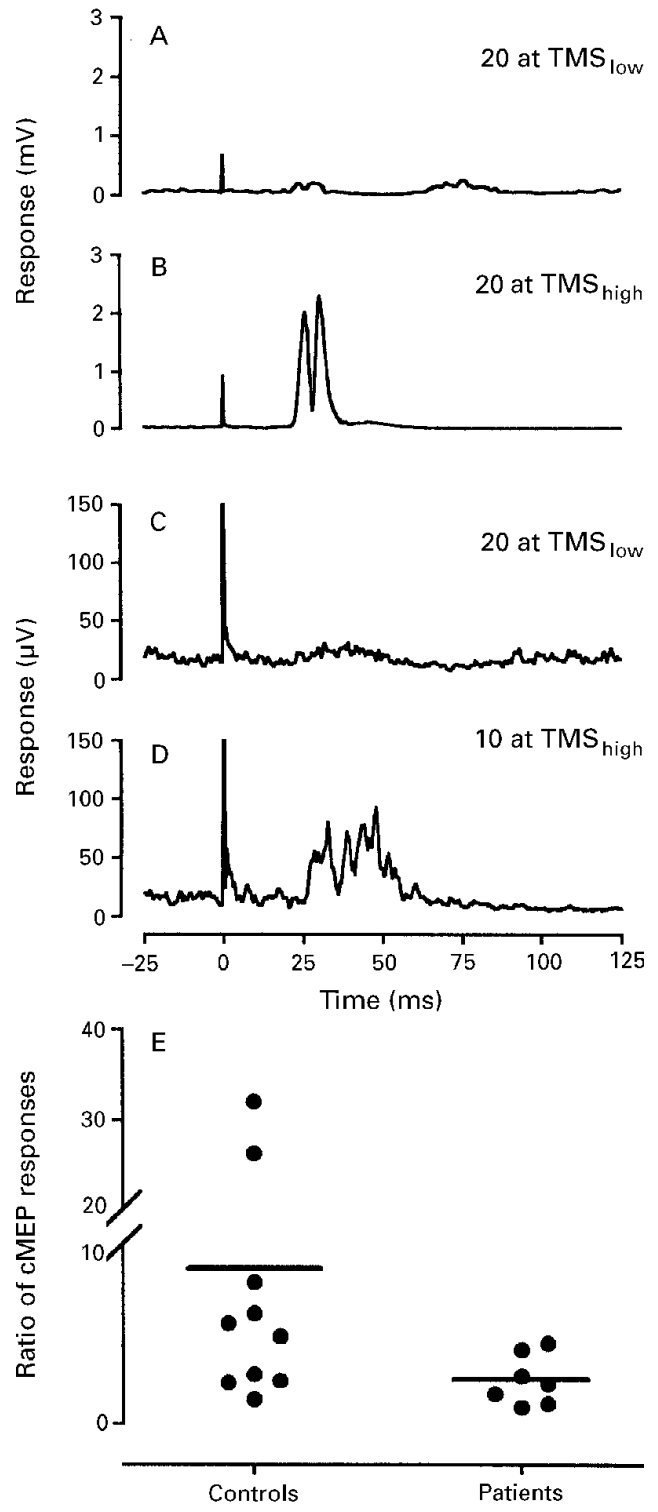

Figure 4 Averaged rectified EMG responses of the thenar muscles to TMS in a control subject ( $A$ and $B$ ) and in a patient (C and D; table, No7) recorded during weak isometric contraction. The number of responses averaged is indicated on each record. Note that increasing the stimulation strength in the control subject results in a larger relative change in cMEP response than in the patient. The scatter graph $(E)$ plots the ratio of the area of the $c M E P$ response at $T M S_{\text {high }}$ to that at $T M S_{\text {low }}$ for control subjects $(n=10)$ and patients $(n=7)$; the horizontal lines indicate the mean.

STIMULUS RESPONSE RELATION: RECRUITMENT OF MOTOR NEURONS

Figure 4 shows records at two different stimulus intensities (see methods) in a control subject ( $\mathrm{A}$ and $\mathrm{B}$ ) and a patient $(\mathrm{C}$ and $\mathrm{D})$.

It is evident from these records that increasing the stimulus intensity in the control subject results in a larger relative increase in the size of the cMEP than in the patient. We investigated recruitment of the response to TMS of the motor cortex in all 10 control subjects and in seven of the patients. Three patients (table, Nos 1, 4, and 10) could not be included in the study as they were unable to tolerate the higher of the two stimulus intensities necessary. The mean value of the ratio: 
average area of cMEP response at $\mathrm{TMS}_{\text {high }}$ average area of cMEP response at $\mathrm{TMS}_{\text {low }}$

for each group (see methods) is indicated by the thick horizontal lines in fig $4 \mathrm{E}$. Although there was clearly overlap between the two groups, the ratio was significantly $(\mathrm{p}<0.05)$ greater in the controls $(9.5(3.4))$ than in the patients $(2.7(0.6))$.

\section{Discussion}

THRESHOLD AND LATENCY: LOCAL EFFECTS OF LESION

The latency and threshold of cMEPs in response to TMS has been used in patients with spinal cord injury to assist with clinical identification of the level and extent of the lesion. ${ }^{27}{ }^{28}$ Indeed, Clarke et $a l^{28}$ have used the technique to help monitor recovery in the period of rehabilitation after injury.

In this study we have found that both threshold and latency of cMEPs in patients with incomplete spinal cord injury are increased in a muscle innervated below the level of the spinal cord lesion. With electrical stimulation of the motor cortex and peripheral nerves, similar increases in latency have been attributed to slowing of conduction velocity of corticospinal tract axons as they pass through the site of the spinal cord lesion. ${ }^{10}$

Weakness of voluntary muscle contraction in patients with incomplete spinal cord injury correlates well with delayed or absent responses in the muscle to TMS. ${ }^{12}$ As corticospinal neurons branch widely to innervate several motor neurons, ${ }^{29}$ a reduced input to those motor neurons will result if the number of active corticospinal neurons is reduced. This might well explain why the threshold stimulus intensity required to evoke cMEPs is higher in patients with incomplete spinal injury. To evoke a descending corticospinal volley of similar efficacy in patients and controls, TMS must be able to recruit other corticospinal neurons in the patients. The axons of some corticospinal neurons will have been damaged at the site of the spinal cord lesion. The damage would have been indiscriminate, such that axons of any size and distribution may have been affected. The reduction in the number of conducting axons could account for our finding that a higher stimulus strength is needed to elicit comparable cMEPs in the patients.

Both latency and threshold for SVC were also increased in the patients with spinal injury. A component of the SVC to TMS results from a reduction of cortical output in normal subjects. ${ }^{21}$ Given that corticospinal axons are damaged as they pass through the site of a spinal lesion, an event in the motor cortex might be expected to exert an effect with longer latency at the level of the motor neurons in the patients. It is likely therefore, that some of the increased latency of SVC results from local slowing of conduction at the lesion site. However, the SVC was found to have a larger increase in latency than the cMEP response, which was also slowed in the patients. There was no significant correlation between the latency of the cMEP and the onset of the SVC for either the patients or the controls (regression analysis, $\mathrm{p}>0.05$ ). One possible explanation for our finding of a relatively long latency of SVC in the patients could be that a different population of corticospinal neurons are involved in producing the weak voluntary contraction than in producing the cMEP response to the magnetic stimulus. However, this is known not to be the case in normal subjects, ${ }^{30}$ in whom the orderly recruitment of motor neurons in a voluntary contraction has been shown to be similar to that seen with TMS of the motor cortex. Despite this, we have preliminary evidence ${ }^{3132}$ to suggest that the recruitment pattern of motor neurons in a voluntary contraction might be different after spinal cord injury. If this is the case, those corticospinal neurons involved in voluntary contraction could have an intrinsically slower conduction velocity or could be affected to a greater degree by local effects of the lesion.

THRESHOLD AND LATENCY: CHANGES ELSEWHERE IN THE CNS

Indiscriminate slowing of corticospinal neurons at the site of injury would lead to a widely dispersed volley from TMS of the motor cortex arriving at the motor neuron pool. Increased summation times for both $\mathrm{D}$ and I waves $^{33}$ arriving at the motor neuron pool could lead to an increased latency of cMEPs after spinal cord injury.

Unlike our control subjects the latency of the cMEP during voluntary contraction in the patients was not shorter than at rest. One reason for this may be that stimulation occurred at the initial segment of corticospinal neurons rather than presynaptically as a result of higher stimulus strengths. ${ }^{14-16}$ However, we cannot exclude the possibility that the pattern of facilitation has been altered after spinal cord injury as a result of cortical reorganisation. ${ }^{34}$

The SVC in response to TMS is due, in part, to a reduction of corticospinal output in response to the TMS. ${ }^{21}$ The SVC occurs at longer latency than the cMEPs found at higher stimulus intensities suggesting that a longer pathway is involved in producing the suppression, presumably involving interneurons within the motor cortex. By contrast with the 13.4 (1.6) ms latency difference between SVC and cMEP response in control subjects, the patients with spinal cord injury showed a difference of 25.3 (2.4) ms. Assuming the cMEP is evoked with the same corticospinal neurons as those involved in production of the voluntary contraction, then the latency difference found is equivalent to an increase in latency of SVC of 11.9 (25.3) -13.4 ms) longer than could realistically be explained by local slowing of conduction at the site of the spinal cord lesion.

We propose that the SVC has at least two components and that the early portion has become weakened or is absent after injury. This weakening of inhibitory processes might contribute to the increased threshold for suppression found in the patients. With paired TMS pulses, Ridding et $a l^{35}$ have shown 
that inhibition is reduced in patients with Parkinson's disease when levodopa treatment was withdrawn overnight. The largest reduction in inhibitory drive was seen with interstimulus intervals of $1-5 \mathrm{~ms}$ suggesting that the inhibition had become weakened during the early portion of the response. Nakamura et $a l^{\beta 6}$ point out that it is the later part of the descending spinal cord volley that is influenced most effectively by a conditioning cortical stimulus. For this reason, the actual timing of the latency of inhibition of motor neurons could be several milliseconds longer than that suggested by the work of Ridding et $a b^{35}$ An increased latency of SVC of $10.5 \mathrm{~ms}$ has also been reported after antidopaminergic medication in patients with schizophrenia, ${ }^{37} 38$ and this is close to the mean value of $11.9 \mathrm{~ms}$ found in the present study. These results are consistent with the suggestion that dopaminergic circuitry involved in production of the early part of SVC may have been altered as part of the natural process of recovery after spinal cord injury.

Six of our patients were taking medication to control spasticity by depressing spinal motoneuron pool excitability (table).$^{39}$ We found no differences in the responses of patients taking antispasticity medication. Inghilleri et al have found that baclofen does not affect the cortical silent period although diazepam has been found to shorten its duration, ${ }^{40}$ suggesting that the later portion of the silent period can be modulated by GABA, altering its duration. In our patients we propose that it is the early portion of the SVC that has become weakenened or abolished, producing an apparent shift in latency. Other work ${ }^{40}{ }^{41}$ investigating the effects of modulating GABAergic neurotransmission on SVC has provided us with pointers for further studies examining the later portion of the silent period after spinal cord injury.

In this study we did not record somatosensory evoked potentials and have no physiological index of the degree to which ascending pathways in the spinal cord are affected by the injury. However, the neurological assessments of sensory function (table) showed deficits in many of the patients. It is probable that deprivation of sensory input to the cortex could be important in the reorganisation of cortical motor function as well as the known adjustments to sensory systems. ${ }^{42} 43$

STIMULUS-RESPONSE RELATION: RECRUITMENT OF MOTOR NEURONS

The ratio of the size of the cMEP produced at $\mathrm{TMS}_{\text {high }}$ to that produced at TMS $\mathrm{S}_{\text {low }}$ during voluntary contraction (see methods) was smaller in the patients $(2.7(0.6))$ than in the control subjects $(9.5$ (3.4)). This suggests that the the growth of the cMEP response with increasing TMS intensity is less pronounced after injury to the spinal cord. The trauma to the spinal cord is likely to have affected corticospinal neurons in an indiscriminate manner so that the distribution of corticospinal neurons of different thresholds may have been changed. The alteration to the pattern of recruitment ${ }^{3132}$ could be ascribed to a reorganisation of excita- tory and inhibitory connections to individual corticospinal neurons at the level of the motor cortex as well as local affects at the site of spinal cord injury and reorganisation in the spinal motor neuron pool.

\section{Conclusion}

This study has disclosed alterations to the corticospinal system after incomplete spinal cord injury. Some of these changes are likely to be the result of the destruction of corticospinal axons or slowing of conduction velocity at the level of the lesion in the spinal cord. However, the changes we have found in cortical inhibition (SVC) are, at least in part, likely to be the result of altered function within the brain.

This study was supported by a project grant from the Wellcome Trust. We thank Staff Nurses Anne McCreath and Cherry Gregory for their help with recruitment of patients and clinical assistance during recording sessions. We are most grateful for the technical assistance and help with analysis provided by the technical assistance and help with analysis provided by the patients at Stoke Mandeville for their involvement in this the patien.
study.

1 Donoghue JP, Sanes JN. Organisation of adult motor cortex representation patterns following neonatal forelimb injury in rats. $\mathcal{F}$ Neurosci 1988;8:3221-32.

2 Merzenich MM, Jenkins WM. Reorganisation of cortical representations of the hand following alterations of skin inputs induced by nerve injury, skin island transfers, and inputs induced by nerve injury, skin is

3 Hall EJ, Flament D, Fraser C, et al. Non-invasive brain stimulation reveals reorganised cortical outputs in amstimulation reveals reorganised cortical
putees. Neurosci Lett 1990;116:379-86.

4 Cohen LG, Banindelli S, Findley TW, et al. Motor reorganisation after upper limb amputation in man. Brain
sat. sation after upp

5 Fuhr P, Cohen LG, Dang N, et al. Physiological analysis of motor reorganization following lower limb amputation. Electroencephalogr Clin Neurophysiol 1992;85:53-60.

6 Brasil-Neto JP, Cohen LG, Pascual-Leone A, et al. Rapid reversible modulation of human motor outputs after ransient deafferentation of the forearm: a study with transcranial magnetic stimulation. Neurology 1992;42:1302-6.

7 Donoghue JP, Suner S, Sanes JN. Dynamic organisation of primary motor cortex output to target muscles in adult rats. II. Rapid reorganisation following motor nerve lesions. Exp Brain Res 1990;79:492-503.

8 Levy JW Jr, Amassian VE, Traad M, et al. Focal magnetic coil stimulation reveals motor cortical system reorganized in humans after traumatic quadriplegia. Brain Res 1990; 510:130-4

9 Topka H, Cohen LG, Cole RA, et al. Reorganisation of corticospinal pathways following spinal cord injury. Neurology ticospinal pathways

10 Chang CW, Lien IN. Estimate of motor conduction in human spinal cord: slowed conduction in spinal cord injury. Muscle Nerve 1991;14:990-6.

1 Brouwer B, Bugaresti J, Ashby P. Changes in corticospinal facilitation of lower limb spinal motor neurons after spinal cord lesion. F Neurol Neurosurg Psychiatry 1991;55:20-4.

12 Machida M, Yamada T, Krain L, et al. Magnetic stimulation: examination of motor function in patients with cervical spine or cord lesion. $\mathcal{F}$ Spinal Disord 1991;4:12330 .

13 Berardelli A, Inghilleri M, Cruccu G, et al. Electrical and magnetic transcranial stimulation in patients with corticospinal damage due to stroke or motor neurone disease. Elecpinal damage due to stroke or motor neurone dis
troencephalogr Clin Neurophysiol 1991;81:389-96.

14 Rothwell JC, Thompson PD, Day BL, et al. Stimulation of the human motor cortex through the scalp. Exp Physiol 1991;76:159-200.

15 Edgley SA, Eyre JA, Lemon RN, et al. Excitation of the corticospinal tract by electromagnetic and electrical stimulaion of the scalp in the macaque monkey. I Physiol 990;425:301-20.

16 Burke D, Hicks RG, Stephen JP. Corticospinal volleys evoked by anodal and cathodal stimulation of the human motor cortex. F Physiol 1990;425:283-99.

7 Rothwell JC, Ferbert A, Caramia MD, et al. Intracortical inhibitory circuits studied in humans. Neurology 1991;41: 192.

18 Wasserman EM, Fuhr P, Cohen LG, et al. Effects of transcranial magnetic stimulation on ipsilateral muscles. Neurology 1991;41:1795-9.

19 Ferbert A, Rothwell JC, Day BL, et al. Interhemispheric inhibition of the human motor cortex. F Physiol 1992;453: 525-46.

20 Kujirai T, Caramia MD, Rothwell JC, et al. f Physiol 1993;471:501-19.

21 Davey NJ, Romaiguère P, Maskill DW, et al. Suppression of voluntary motor activity revealed using transcranial magnetic stimulation of the motor cortex in man. F Physiol 1994;477:223-35. 
22 Davey NJ, Wells E, Maskill DW, et al. Cortical motor function in spinal cord injury patients. Abstracts Society for Neution in spinal cord injury
roscience $1995 ; 21: 172.7$.

23 Maynard MF Jr, Bracken MB, Creasey G, et al. International standards for neurological and functional classification of spinal cord injury. Spinal Cord 1997;35: 256-74.

24 Day BL, Dressler D, Hess CW, et al. Direction of current in magnetic stimulating coils used for percutaneous activation of brain, spinal cord and peripheral nerve. $\mathcal{f}$ Physiol 1990;430:617.

25 Rossini PM, Barker AT, Berardelli A, et al. Non-invasive electrical and magnetic stimulation of the brain, spinal cord and roots: basic principles and procedures for routine clinical application. Report of an IFCN committee. Electroencephalogr Clin Neurophysiol 1994;91:79-92.

26 Widmer CG, Lund JP. Evidence that peaks in EMG averages can sometimes be caused by inhibition of averages can sometimes be caused by in

27 Ackermann H, Thomas C, Guschlbauer B, et al. Neurophysiological evaluation of sensorimotor functions of the physiological evaluation of sensorimotor functions of the leg: comparison of evoked cortical potentials following electrical and mechanical stimulation, long-latency muscle responses and tran

28 Clarke CE, Modarras-Sadeghi $\mathrm{H}$, Twomey JA, et al. Prognostic value of cortical magnetic stimulation in spinal cord injury. Paraplegia 1994;32:554-60.

29 Bennett KM, Lemon RN. The influence of single monkey cortico-motoneuronal cells at different levels of activity in target muscles. F Physiol 1994;477:291-307.

30 Bawa P, Lemon RN. Recruitment of motor units in response to transcranial magnetic stimulation in man. 7 Physiol 1993;471:445-64.

31 Smith HC, Davey NJ, Maskill DW, et al. Recruitment of motoneurones by transcranial magnetic stimulation in spinal cord injury. Abstracts Society for Neuroscience 1996;22: 58.17 .

32 Smith HC, Davey NJ, Maskill DW, et al. Recruitment and facilitation of the corticospinal system revealed using transcranial magnetic stimulation in incomplete spinal cord injury patients. $\mathcal{F}$ Physiol 1997;501:43P.
33 Kaneko K, Kawai S, Fuchigami Y, et al. Effect of stimulus intensity and voluntary contraction on corticospinal potenSci 1996;139:131-6.

34 Davey NJ, Smith HC, Maskill DW, et al. Facilitation of corticospinal pathways with increasing voluntary contraction in spinal cord injury. Abstracts Society for Neuroscience 1996; 22:58.18

35 Ridding MC, Inzelberg R, Rothwell JC. Changes in cortical excitability of motor cortical circuitry in patients with Pakinson's disease. Ann Neurol 1995;37:181-8.

36 Nakamura H, Kitagawa H, Kawaguchi Y, et al. Intracortical facilitation and inhibition after paired magnetic stimulation in humans under anaesthesia. Neurosci Lett 1995;199:155-

37 Davey NJ, Puri BK, Lewis HS, et al. Electromyographic responses of thenar muscles to transcranial magnetic stimulation of the motor cortex in schizophrenic patients. $\mathcal{F}$ Physiol 1995;489:31P.

38 Davey NJ, Puri BK, Lewis HS, et al. The effects of antipsychotic medication on electromyographic responses to transcranial magnetic stimulation of the motor cortex in schizophrenia. 7 Neurol Neurosurg Psychiatry 1997;63:46873

39 Milanov IG. Mechanisms of baclofen action on spasticity. Acta Neurol Scand 1992;85:305-10.

40 Inghilleri $\mathrm{M}$, Berardelli A, Marchetti $\mathrm{P}$, et al. Effects of diazepam, baclofen and thiopental on the silent period evoked by transcranial magnetic stimulation in humans. Exp Brain Res 1996;109:467-72.

41 Ziemann U, Lonnecker S, Steinhoff BJ. et al. Effects of antiepileptic drugs on motor cortex excitability in humans: transcranial magnetic stimulation study. Ann Neurol 1996;40:367-78.

42 Rossini PM, Martino G, Narici L, et al. Short-term brain "plasticity" in humans: transient finger representation changes in sensory cortex somatotopy following ischemic anesthesia. Brain Res 1995;642:169-77.

43 Rausell E, Jones EG. Extent of intracortical arborization of thalamocortical axons as a determinant of representational plasticity in monkey somatic sensory cortex. $\mathcal{F}$ Neurosci 1995;15:4270-88. 